\title{
Nondestructive Testing of Nonmetallic Pipelines Using Microwave Reflectometry on an In-Line Inspection Robot
}

DOI:

10.1109/TIM.2018.2847780

\section{Document Version}

Accepted author manuscript

Link to publication record in Manchester Research Explorer

\section{Citation for published version (APA):}

Carrigan, T., Forrest, B. E., Andem, H. N., Gui, K., Johnson, L., Hibbert, J., Lennox, B., \& Sloan, R. (2018).

Nondestructive Testing of Nonmetallic Pipelines Using Microwave Reflectometry on an In-Line Inspection Robot. IEEE Transactions on Instrumentation and Measurement , 1-9. https://doi.org/10.1109/TIM.2018.2847780

\section{Published in:}

IEEE Transactions on Instrumentation and Measurement

\section{Citing this paper}

Please note that where the full-text provided on Manchester Research Explorer is the Author Accepted Manuscript or Proof version this may differ from the final Published version. If citing, it is advised that you check and use the publisher's definitive version.

\section{General rights}

Copyright and moral rights for the publications made accessible in the Research Explorer are retained by the authors and/or other copyright owners and it is a condition of accessing publications that users recognise and abide by the legal requirements associated with these rights.

\section{Takedown policy}

If you believe that this document breaches copyright please refer to the University of Manchester's Takedown Procedures [http://man.ac.uk/04Y6Bo] or contact uml.scholarlycommunications@manchester.ac.uk providing relevant details, so we can investigate your claim.

\section{OPEN ACCESS}




\title{
Nondestructive Testing of Non-Metallic Pipelines Using Microwave Reflectometry on an In-Line Inspection Robot
}

\author{
Tobias D. Carrigan, Benjamin E. Forrest, Hector N. Andem, Kaiyu Gui, Lewis Johnson, James E. \\ Hibbert, Barry Lennox, Senior member, IEEE, and Robin Sloan, Senior member, IEEE
}

\begin{abstract}
Microwave and millimeter wave reflectometry, a form of continuous-wave surface penetrating radar, is an emerging non-destructive inspection technique that is suitable for non-metallic pipelines. This article shows a K-band microwave reflectometry instrument implemented onto an in-line pipecrawling robot, which raster-scanned cracks and external wall loss on a high-density polyethylene (HDPE) pipe of diameter $150 \mathrm{~mm}$ and wall thickness $9.8 \mathrm{~mm}$. The pipe was scanned with three environments surrounding the pipe that approximated the use cases of over-ground HDPE pipelines, plastic-lined metal pipes, and undersea HDPE pipelines. The instrument was most sensitive when cracks were oriented parallel to its magnetic (H) plane. Any small variation in the standoff distance between the instrument's probe antenna and the pipe wall, which was not easy to avoid, was found to obscure the image. To mitigate this problem, a sensitivity analysis showed that an optimal frequency can be chosen at which standoff distance can vary by up to $\mathbf{\pm 0 . 7 5} \mathbf{~ m m}$ within a certain range without distorting the indications of defects on the image.
\end{abstract}

Index Terms-Crack detection, microwave reflectometry, nondestructive testing, polarization, polyethylene, pipelines, electromagnetic reflection, electromagnetic scattering

\section{INTRODUCTION}

$\mathrm{T}$ HE inspection of pipelines is of great importance in the oil, gas and water industries to manage the risk of catastrophic burst failures. Non-metallic pipelines, such as HDPE (highdensity polyethylene), are increasingly adopted in these industries [1]. HDPE pipe is more corrosion-resistant than steel pipe, but as with most materials, defects can occur in the pipewall that affect its structural integrity.

Underground and undersea pipelines are generally difficult to externally access, so they are typically inspected using an inline inspection device - a pipe crawler fitted with instruments that inspect the pipe wall around it for defects [2]. Existing inline inspection devices are designed for conventional metallic

Manuscript received January 31, 2018; revised April 5, 2018; accepted May 20, 2018. This work was performed as part of an M.Eng. degree-level project at the University of Manchester.

J. E. Hibbert and B. Lennox are with the Department of Engineering and Physical Sciences, University of Manchester, Manchester M13 9PL, UK (emails: james.hibbert@postgrad.manchester.ac.uk and barry.lennox@manchester.ac.uk respectively).

T. D. Carrigan, B. E. Forrest, H. N. Andem, K. Gui, L. Johnson, and R. Sloan were with the Department of Engineering and Physical Sciences, University of Manchester, Manchester M13 9PL, UK. T. D. Carrigan is now with the pipelines, and the inspection techniques they use, such as the eddy current and magnetic flux leakage techniques, are unsuitable for non-metallic pipelines [3-5]. Ultrasound, another common technique, has been trialed for inspecting welds in HDPE pipe with little success [6, 7].

Microwave reflectometry imaging is an emerging technique that has been proven to identify defects in non-metallic materials including HDPE. This technique interrogates the material's physical structure with electromagnetic waves at microwave and millimeter wave $(300 \mathrm{MHz}$ to $300 \mathrm{GHz}$ ) frequencies [8].

Microwave inspection devices operating from $200 \mathrm{MHz}$ to $2.6 \mathrm{GHz}$ have been fitted to pipe crawlers deployed in concrete sewer pipes to detect large anomalies in the pipe and its surrounding soil [9-11]. This article presents a pipe inspection apparatus operating in the K-band (18 to $26.5 \mathrm{GHz}$ ) aiming to identify smaller defects that affect the safe operation of pressurized pipelines. A detailed analysis of the practical considerations of implementing the microwave reflectometry technique on a pipe crawler is given. An important consideration is that variations in the antenna's standoff distance from the pipe wall affect the measurements and obscure indications of defects, unless optimal signal frequencies and standoff distance ranges are selected. These optimal parameters were evaluated that allow variation in standoff distance within an optimal range without obscuring the image.

The types of defect that commonly occur in HDPE piping will be reviewed, followed by theory, practical considerations, and experimental evaluations.

\section{FAILURE MODES IN HDPE}

Defects in the pipe wall can occur at any point in its lifetime and are caused by manufacturing faults, abrasion by the pipe

Department of Engineering, University of Cambridge, Cambridge CB2 1PZ, UK (e-mail: tdc41@cam.ac.uk). B. E. Forrest is now in further study at Wuhan, China (e-mail: info@benjaminforrest.co.uk). H. N. Andem is now with Bombardier Transportation UK Ltd., Derby DE24 8AD, UK (e-mail: hector.andem@rail.bombardier.com). K. Gui is now with Grass Capital, Yuanshen Road, Pudong New district, Shanghai, China (e-mail: guikaiyualex@gmail.com). L. Johnson is now with Applied Industrial Systems, Brentford TW8 0GP, UK (e-mail: lewisjohnson190294@ gmail.com). R. Sloan is now with Microwave Inspection Technologies Limited, Warrington WA3 5QX, UK (e-mail: rob.sloan@mwave-inspect.co.uk). 
contents, geographic conditions, and other factors [12]. The type of failure mode is characterized by the amount and duration of stress applied to the pipe wall. Ductile failure results from large transient stresses exceeding the material's yield, whereas a continuous or repetitive stress can lead to a process of slow crack growth [1]. The latter is characterized by brittle separation (cracking) of the material over time, which gradually weakens the pipe wall and eventually leads to failure. Slow crack growth is attributed to long-term pipe failures and can be more difficult to detect due to the lack of deformation in the pipe wall.

Shorter-term failures are caused by defects induced during manufacture and installation, especially improperly-formed fusion welds joining sections of pipe together [13]. A number of researchers have evaluated the use of microwave reflectometry to inspect the quality of fusion welds during installation of the pipe [7]. According to Stakenborghs [14] and Zhu [7], a good weld appears as a uniform vertical line in the microwave scan image, whereas defects in the weld show up as discontinuities or variations in that line.

The present project investigated the detection of mechanical defects — cracks and gouges (material loss) — on the pipe's outer surface. The required sensitivity of the microwave instrument is dictated by the smallest size of crack that needs to be detected. The plastic pipe institute [15] recommends that pipes with any defect spanning more than $10 \%$ of the pipe wall's thickness in depth should be discarded, and this rule is widely adopted by industry. However, Brown [16] suggested shorter depth limits from $8 \%$ of wall thickness $(2.1 \mathrm{~mm})$ for $25 \mathrm{~mm}$ thick pipe down to $3 \%$ of thickness $(2.5 \mathrm{~mm})$ for $83 \mathrm{~mm}$-thick pipe for a 100-year lifetime, according to a study predicting the lifetime of polyethylene pipes subject to slow crack growth. For smaller pipes, Brown's [16] calculated depth limits are more relaxed.

\section{THEORY OF MICROWAVE REFLECTOMETRY}

Microwave reflectometry is performed using a reflectometry instrument connected to a moving probe antenna. The probe transmits a continuous microwave beam into the material, which is backscattered as it passes through discontinuities in permittivity along the path through the material. The probe receives an aggregation of the backscattered signals directed towards it. The reflectometry instrument calculates the reflectivity (complex $S_{11}$-parameter) of the area of material that the probe is viewing from the backscattered signals. Any discontinuities in the material's structure, such as cracks, vary the magnitude and phase of the reflectivity measurement relative to that of the surrounding flawless material.

It is important to note that the signal's interaction with material in the probe's near-field region is very complex, because the signal diverges from the $\mathrm{TE}_{10}$ mode inside the waveguide to a sum of all potential modes just outside its aperture before forming a coherent TEM wave in the far-field region. This is the basis of mode matching theory and is outside this article's scope.

To 'scan' or 'image' the material, measurements of reflectivity, $S_{11}$, are taken with the probe positioned consecutively at a raster grid of point locations over the material surface. Discontinuities in the material 'perturb' the magnitude and phase of $S_{11}$ as the probe passes over them, and hence appear as patches in the 2-dimensional scan image. The image may then be post-processed to optimize the identifiability of defects.

\section{A. Design and performance parameters}

One of the performance characteristics of a reflectometry system is the sensitivity of the probe to a defect, which is defined in this article as the peak-to-peak departure in the magnitude or phase of $S_{11}$ away from its background level as the probe scans over that defect, excluding noise.

The probe's near-field region is often used as the sensitivity there is much higher than in the far-field region [17]. The nearfield has a limited penetration depth into the material that is dependent on the probe design and material's permittivity. The spatial resolution of the scan image is determined by the probe's near-field footprint and far-field beam-width, depending on the distance away from the probe. With a K-band open-ended waveguide, a small defect typically appears as a $10-20 \mathrm{~mm}$ wide indication in the image. Improvements in both penetration depth and resolution have been demonstrated by a horn antenna fitted with a slotted aperture or dielectric lens [18].

\section{B. Standoff distance}

The measured $S_{11}$ is dependent on the entire environment within the probe's beam. The standoff distance between the probe and the material under test is an important parameter since any variations in this distance as little as $0.05 \mathrm{~mm}$ have a large, unwanted effect on $S_{11}$ that can obscure indications of defects $[8,19]$. The standoff distance of a rotating probe on a pipe crawler will vary if the probe's rotational axis is off-center or if the pipe is not perfectly circular.

One approach to reduce unwanted effects is to measure the standoff distance and either mechanically control this distance or post-process the measurement data to remove interference from changes in standoff distance [19].

Alternatively, combinations of microwave signal frequency and standoff distance range were found within which at least one component of $S_{11}$ has a near-linear relationship with standoff distance that preserves the shape and amplitude of the defects' perturbations. Linear trends can be removed from the scan image using a simple least-mean-square fit algorithm, resulting in a scan that is nearly unaffected by variations within a certain range of standoff distances. This approach was used in this investigation to avoid the need for the pipe crawler prototype to control the standoff distance more accurately than $\pm 0.75 \mathrm{~mm}$. The method used to determine the optimal frequencies and standoff distances is described in section V.B.

Variations in standoff distance are normally gradual and sinusoidal over a single rotation of the probe inside the pipe. Any sudden or excessive changes can indicate bulging in the pipe wall and should remain identifiable in the image.

\section{Synthetic Aperture Radar (SAR) imaging}

Synthetic aperture radar (SAR) has been used by some 
researchers to improve the quality of scan images $[17,20]$. It involves scanning the material at a wide band of signal frequencies and reconstructing a 3-dimensional image of the permittivity distribution within the material. It maintains a constant resolution throughout the material's thickness [17]. 3D imaging can be advantageous in pipeline environments as it can exclude unwanted reflections from inhomogeneous environments inside and outside the pipe.

SAR techniques typically use the probe's far-field region to alleviate the issues with its near-field region including limited range, and achieve far better sensitivity and resolution than is otherwise possible with single-frequency measurements. This enables the identification of smaller cracks further away from the probe, as demonstrated by Ghasr [17].

The drawbacks of SAR techniques are that they are complex to implement and require wideband microwave instrumentation. SAR would be worthy in a longer study and was deemed beyond the scope of this reported work.

\section{EQUIPMENT}

The scanning equipment is made up of three major parts. The microwave instrumentation consisted of a network analyzer configured to measure $S_{11}$ through a moving probe. A mechanical apparatus such as the pipe crawler positions and scans the probe over the material under test such as the pipe's inner surface. A computer controls and acquires measurements from the network analyzer and the mechanical apparatus in order to scan the material.

\section{A. Microwave instrumentation}

The microwave probe was made up of a section of K-band $(18-26.5 \mathrm{GHz})$ waveguide, with a flangeless open-ended aperture, connected to a waveguide-to-coaxial adapter. The adapter was connected to a Keysight N9918A vector network analyzer (VNA). The network analyzer was calibrated up to the adapter's waveguide port using short, offset short, and load waveguide standards. The remaining phase shift due to the open-ended waveguide section's length of $47.8 \mathrm{~mm}$ was compensated in software.

The network analyzer was located outside the pipe due to its size, and was tethered to the probe on the pipe crawler by a coaxial cable. This is sufficient to evaluate the microwave inspection technique in the lab. Smaller-sized microwave instrumentation can be designed to fit within a pipe crawler in future work.

\section{B. Pipe crawler prototype}

A robotic pipe crawling apparatus, illustrated in Fig. 1, was created to position and scan the microwave probe within the pipe. The pipe crawler consisted of two sets of three wheels that were sprung against the pipe wall. The rear set was motorized to position the pipe crawler. Rotary encoders were fitted to the front set of wheels to measure the linear distance travelled. A rotating clamp head on the front of the robot held the probe and controlled its angular position.

\section{EXPERIMENTAL RESULTS}

To demonstrate the practical utility of the microwave

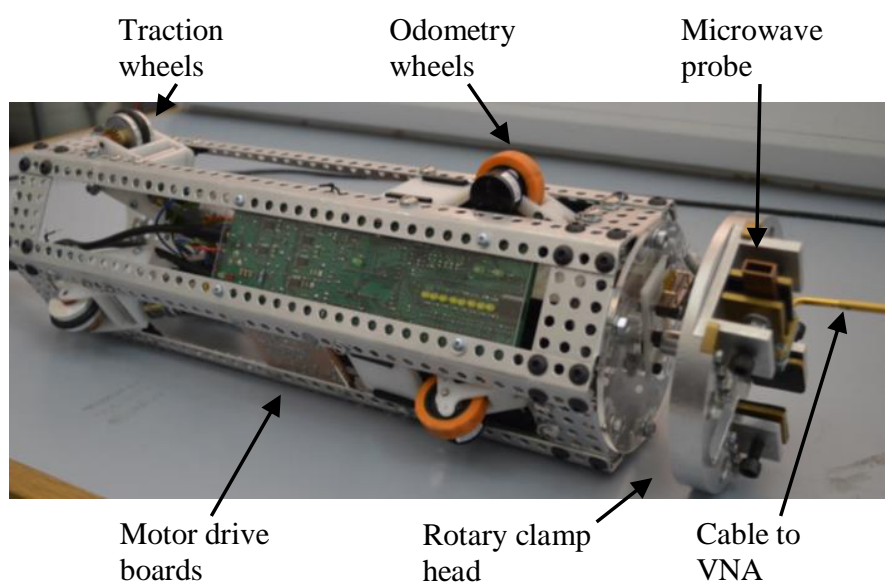

Fig. 1. Prototype of pipe crawler with microwave waveguide probe clamped onto its rotary scanning head.

reflectometry technique, samples of HDPE pipe containing defects were scanned using the pipe crawler prototype and microwave instrument. The pipe's nominal external diameter was $160 \mathrm{~mm}$ and its wall thickness was $9.8 \mathrm{~mm}$.

Firstly, 1-dimensional scans were performed to determine the scan parameters - polarization, signal frequency, and standoff distance - that give the most optimal detectability for defects [8]. The sensitivity of the instrument to narrow rectangular defects at different polarizations was examined on a flat HDPE sheet (as it was impractical to reorient the probe inside the pipe due to its cable connection). The optimal frequencies and standoff distances were then determined for the HDPE pipe, with comparisons to those of the flat sheet.

One pipe sample containing eight defects was then 2dimensionally scanned using the pipe crawling apparatus. Notches were cut to various depths on the pipe sample's outer surface to represent cracks, and holes were partially drilled to represent physical damage such as gouges.

The following three environments surrounding the pipe were tested:

- Free space (no foil backing): a clean environment with at least 1 meter of free space in the $60^{\circ}$ sectors each side of the defects

- Reflective aluminum foil backing wrapped over the defects

- Saltwater (aqueous sodium chloride solution) of conductivity $35 \mathrm{~S} / \mathrm{m}$ sealed inside the notches and holes using plastic film, and aluminum foil wrapped over.

The free-space environment represents above-ground pipelines. The foil backing represents a plastic-lined metal pipe, where the defects are gas-filled cracks and voids in the plastic liner. Generally, the plastic pipe rests loosely inside the metal pipe, creating varying air gaps between the plastic and metal pipe surfaces. This is beyond scope of the present investigation, so a tight fit between the plastic and metal surfaces is assumed.

For the $3^{\text {rd }}$ environment, saltwater inside the defects and under foil backing was chosen to represent clean conditions around subsea pipelines. Aluminum foil was used to represent this body of saltwater since it was impractical to enact a large body of saltwater around the pipe. 


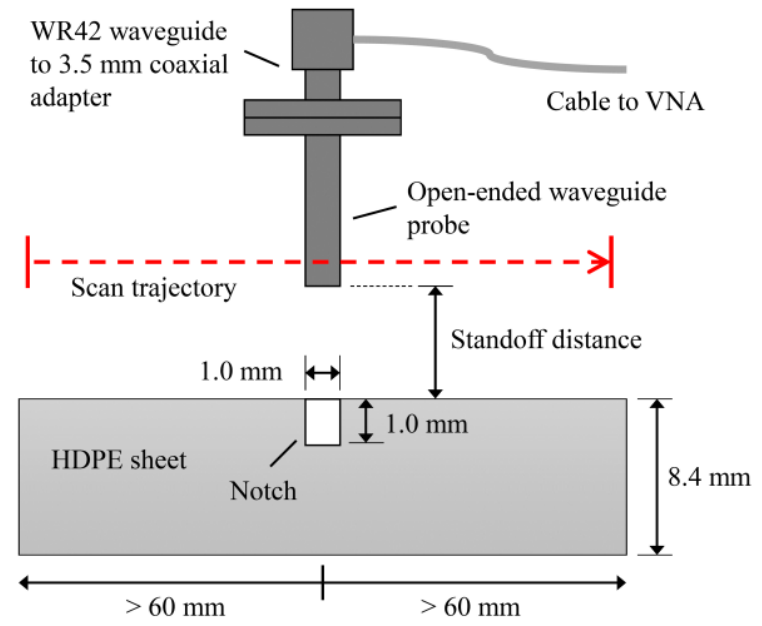

Fig. 2. Test setup for scans of HDPE sheet, showing the microwave probe with its aperture positioned at a standoff distance from the material surface.

\section{A. Polarization}

Electromagnetic waves consist of transverse electric and magnetic fields at $90^{\circ}$ to each other. Since the microwave probe is single-polarized, the sensitivity to long, narrow defects such as cracks is dependent on the defect's polar orientation with respect to the probe's electric $(\mathrm{E})$ or magnetic $(\mathrm{H})$ planes.

To examine this relationship, the probe was mounted on an $\mathrm{X}-\mathrm{Y}-\mathrm{Z}$ positioner to scan over a flat HDPE sheet of thickness $8.4 \mathrm{~mm}$ at a standoff distance of $2.5 \mathrm{~mm}$, as illustrated in Fig. 2. A $40 \mathrm{~mm}$-long rectangular notch was cut to a width of $1 \mathrm{~mm}$ and depth of $1 \mathrm{~mm}$ on the top face of the HDPE sheet, which was placed on a reflective aluminum sheet backing. In each scan, 160 point measurements were taken along a straight line of length $40 \mathrm{~mm}$ perpendicular to the notch, crossing the notch centrally. The network analyzer measured $S_{11}$ at 401 frequencies from 18 to $26.5 \mathrm{GHz}$ at each point. Scans were performed with the notch oriented parallel to the probe's Hplane, E-plane, and diagonally $\left(45^{\circ}\right)$ between the planes.

The sensitivity of the probe to the notch was calculated at each frequency from the magnitude and phase components of $S_{11}$ separately, and plotted in Fig. 3. Sensitivity was calculated by taking the difference between the lowest and highest $S_{11}$ measurements in the scan after removing noise and linear trends. It can be seen that the probe has double the magnitude sensitivity to notches oriented in its H-plane than in its E-plane at most frequencies. The diagonal polarization can be seen as a compromise between the H-plane and E-plane. Therefore, if the
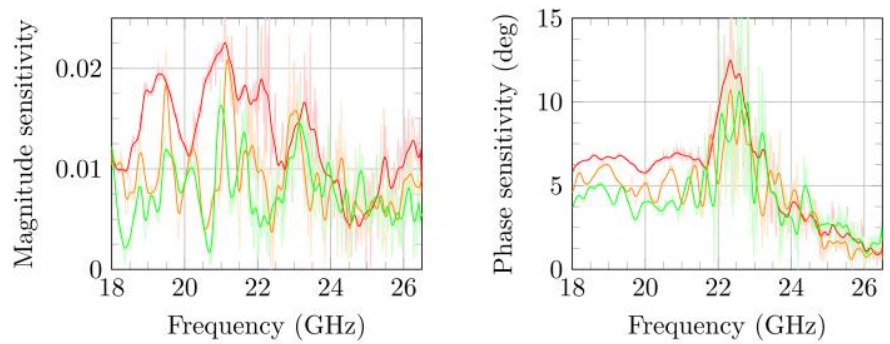

$$
\text { Notch orientation: — H-plane _ Diagonal _ E-plane }
$$

Fig. 3. Sensitivity of the magnitude and phase of $S_{11}$ to a $1 \times 1 \mathrm{~mm}$ notch on the flat HDPE sheet at different polar orientations - smoothed for clarity. probe is oriented diagonally to the pipe's axis, it can equally detect cracks in both the axial and circumferential orientations on the pipe. Alternatively, higher sensitivity can be achieved by using a dual-polarized probe, such as a circular waveguide with an orthomode transducer.

\section{B. Optimizing frequency and standoff distance}

The optimal combinations of signal frequency and standoff distance range were determined by testing the microwave instrument on a sample of the HDPE pipe. The use of optimal combinations was found to enable clear imaging with good sensitivity even if the standoff distance varies within the optimal range during the scan.

A notch of width $1 \mathrm{~mm}$ and depth $2 \mathrm{~mm}$ was cut on the pipe sample's outer surface in the axial direction. The rotating clamp head (separated from the pipe crawler) was affixed inside the pipe and configured to scan the probe along a single slice through the middle of the notch.

The pipe was scanned by taking measurements of $S_{11}$ from 18 to $26.5 \mathrm{GHz}$ at 128 equally-spaced points spanning a $44.5^{\circ}$ sector of the pipe $(62.1 \mathrm{~mm}$ along the pipe's outer circumference), with the notch near the mid-point. Scans were taken at a set of standoff distances from $1 \mathrm{~mm}$ to $4 \mathrm{~mm}$, accurate to $\pm 0.25 \mathrm{~mm}$.

A defect can be reliably identified in conditions of varying standoff distance if the shape of its perturbation on the $S_{11}$ value is nearly constant with standoff distance. The change in the shape of the perturbation was quantified at each frequency by calculating the RMS (root-mean-square) difference between the two perturbations, excluding their offsets and linear trends (least-mean-square fits), at the upper and lower bounds of the selected standoff distance range. It was found by observation that the change in perturbation shape is acceptable if the RMS

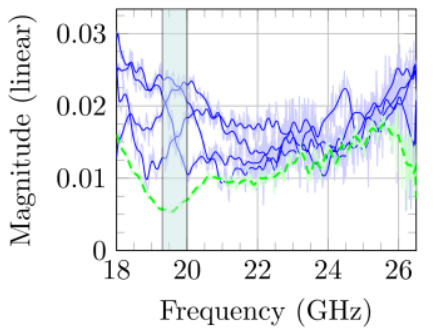

(a) no foil backing: magnitude

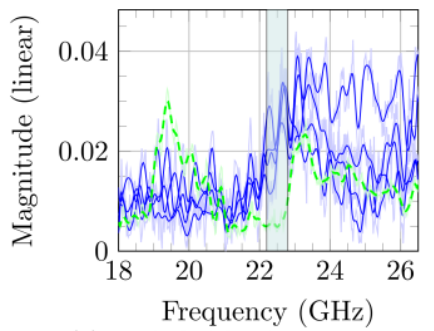

(c) with foil backing: magnitude

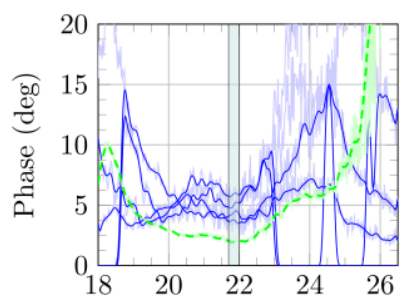

Frequency $(\mathrm{GHz})$

(b) no foil backing: phase

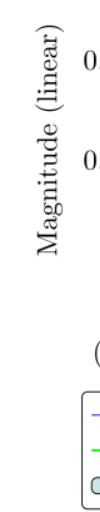

- Sensitivity at standoff distances from 1.5 to $3.0 \mathrm{~mm}$

--- RMS difference in $S_{11}$ between standoffs of 1.5 and $3.0 \mathrm{~mm}$

$\hookrightarrow$ Optimal region for standoff distances from 1.5 to $3.0 \mathrm{~mm}$

Fig. 4. Sensitivity and RMS difference (over frequency) of magnitude and phase components of $S_{11}$ for a $1 \times 2 \mathrm{~mm}$ notch on the outer surface of HDPE pipe, and optimal regions for probe standoff distances from 1.5 to $3.0 \mathrm{~mm}$. 
TABLE I

OPTIMAL FREQUENCIES AND STANDOFF DISTANCES BETWEEN MICROWAVE PROBE AND HDPE MATERIALS

\begin{tabular}{lllllll}
\hline \hline $\begin{array}{c}\text { HDPE } \\
\text { material } \\
\text { under test }\end{array}$ & Backing & $\begin{array}{c}\text { Side of notch } \\
\text { relative to } \\
\text { probe }\end{array}$ & $\begin{array}{c}\text { Optimal frequencies } \\
\text { for magnitude } \\
\text { component [GHz] }\end{array}$ & $\begin{array}{c}\text { Optimal standoff distance } \\
\text { range for magnitude } \\
\text { component [mm] }\end{array}$ & $\begin{array}{c}\text { Optimal frequencies } \\
\text { for phase component } \\
\text { [GHz] }\end{array}$ & $\begin{array}{c}\text { Optimal standoff } \\
\text { distance range for phase } \\
\text { component [mm] }\end{array}$ \\
\hline Pipe $^{1}$ & None & Far side & $19.3-20.0$ & $1.5-3.0$ & $21.7-22.0$ & $1.5-3.0$ \\
Pipe $^{1}$ & Aluminum foil & Far side & $22.2-22.8$ & $1.5-3.0$ & $23.8-24.4$ & $1.5-3.0$ \\
Sheet $^{2}$ & Aluminum & Far side & a) $18.5-18.7$, & a) $1.0-2.0$, & a) $19.3-20.0$, & a) $1.0-3.0$, \\
& sheet & Near side & b) $25.2-26.0$ & b) $1.5-4.0$ & b) $25.0-26.5$ & b) $2.5-5.0$ \\
Sheet $^{2}$ & Aluminum & a) $18.8-19.8$, & a) $3.0-5.0$, & $18.0-20.6$ & $1.0-3.0$ \\
& sheet & & b) $23.2-24.0$ & b) $1.0-2.5$ & & \\
\hline \hline
\end{tabular}

${ }^{1}$ Pipe of wall thickness $9.8 \mathrm{~mm}$ and outer diameter $160 \mathrm{~mm}$

${ }^{2}$ Flat HDPE sheet of thickness $8.4 \mathrm{~mm}$

${ }^{3}$ Notches were oriented parallel to the probe's H-plane; the far side is the side of the material facing away from the probe

difference is below half of the minimum value of sensitivity within that range, and this was selected as the criterion for an optimal combination of frequency and standoff distance range. The selection of this criterion was subjective, so it is advisable to test it against the requirements of each application.

The sensitivity and RMS differences between standoff distances from 1.5 to $3.0 \mathrm{~mm}$ were calculated from scans of the pipe with and without aluminum foil backing and are shown in Fig. 4. The sensitivity graphs (solid blue lines) are smoothed for clarity - the original data are shown as pale-colored lines behind the smoothed data. The graphs of phase sensitivity are also pulled to zero at frequencies where their corresponding magnitude of $S_{11}$ drops below 0.08 , since the phase component is less accurate if the reflected signal received is weak.

The optimal frequency ranges are highlighted in the graphs in Fig. 4 and listed in Table I. Specific frequencies from the optimal ranges were then chosen for the 2-dimensional scans in the next section and are listed in Table II.

To illustrate the implications of the choice of frequency and standoff distances on the quality of the scan image, the 1dimensional scan lines of the notch on the pipe at the chosen frequencies are shown in Fig. 5 for standoff distances from 1.0 to $4.0 \mathrm{~mm}$. It can be confirmed that the perturbations in each of

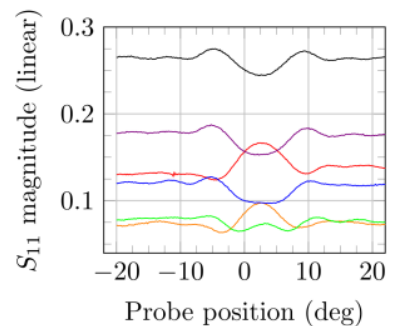

(a) no foil: magnitude at $18.0 \mathrm{GH}$

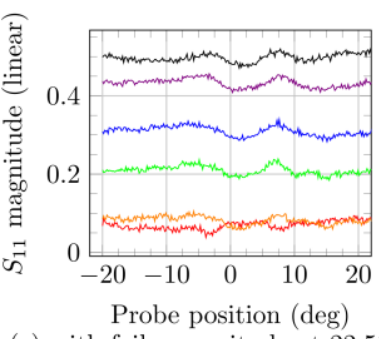

(c) with foil: magnitude at $22.51 \mathrm{GHz}$

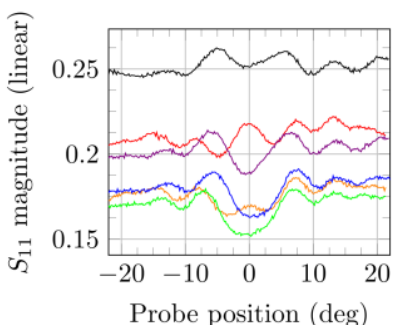

(b) no foil: magnitude at $19.53 \mathrm{GHz}$

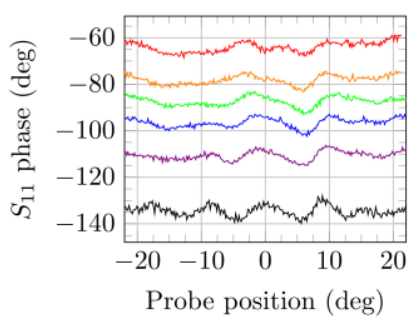

(d) with foil: phase at $24.04 \mathrm{GHz}$

$$
\begin{array}{|l}
\text { Standoff distance: }-1.0 \mathrm{~mm}-1.5 \mathrm{~mm}-2.0 \mathrm{~mm} \\
-2.5 \mathrm{~mm}-3.0 \mathrm{~mm}-4.0 \mathrm{~mm} \\
\hline
\end{array}
$$

Fig. 5. Comparison of perturbations on $S_{11}$ (scan lines) by a $1 \times 2 \mathrm{~mm}$ notch on the outer surface of HDPE pipe for different standoff distances, signal frequencies and backings.
TABLE II

SELECTED OPTIMAL FREQUENCIES FOR 2D PIPE SCANS

\begin{tabular}{llll}
\hline \hline \multicolumn{1}{c}{ Backing } & $\begin{array}{c}\text { Component } \\
\text { of } S_{11}\end{array}$ & $\begin{array}{c}\text { Frequency } \\
{[\mathrm{GHz}]}\end{array}$ & $\begin{array}{c}\text { Standoff distance } \\
\text { range [mm] }\end{array}$ \\
\hline None & Magnitude & 19.5 & $1.5-3.0$ \\
Aluminum foil & Magnitude & 22.5 & $1.5-3.0$ \\
Aluminum foil & Phase & 24.0 & $1.5-3.0$ \\
\hline \hline
\end{tabular}

Fig. 5 (b), (c), and (d) are nearly equivalent in shape between standoff distances of $1.5 \mathrm{~mm}$ and $3.0 \mathrm{~mm}$. The perturbations differ significantly outside this range - at $1.0 \mathrm{~mm}$ and $4.0 \mathrm{~mm}$.

An example of a non-optimal combination of frequency and standoff distance range is $18.0 \mathrm{GHz}$ and $1.0 \mathrm{~mm}$ to $2.5 \mathrm{~mm}$ respectively, within which the perturbations vary in shape with standoff distance as seen in Fig. 5 (a). An optimal combination can, however, be found between $2.5 \mathrm{~mm}$ and $4 \mathrm{~mm}$ in the same graph.

A significant gradient in $S_{11}$ with standoff distance is unavoidable in the setups with aluminum foil backing because of the strong reflection from this backing. The average magnitude or phase level of the scans in Fig. 5 (c) and (d) between standoff distances of $1.5 \mathrm{~mm}$ and $3.0 \mathrm{~mm}$ are spaced apart nearly uniformly by 3 times and 1.5-2 times the sensitivity (amplitude of perturbation) every $0.5 \mathrm{~mm}$ change in standoff distance respectively. These gradients are significant but linear and can be removed by detrending the scan.

A major limitation of relying on optimal frequency and standoff distance combinations is that these are highly dependent on the thickness of the pipe wall and the pipe's external environment. The former dependency is evident since the optimal frequency ranges for scanning the $8.4 \mathrm{~mm}$-thick HDPE sheet in section V.A, also listed in Table I, do not overlap with the optimal range for the $9.8 \mathrm{~mm}$-thick pipe wall with aluminum backing.

Furthermore, the optimal frequencies differed between the sides of the sheet facing towards (near) and away (far) from the probe: there is no overlap between the optimal frequency ranges on the near and far sides of the sheet for the magnitude component, although there is a useful overlap for the phase component. This can be explained by the interaction of nearfield evanescent waves being less predictable than far-field propagating waves. It can be concluded that the ability to identify small defects in all parts of the pipe wall can only be ensured by thorough testing for each environment and pipe size. 


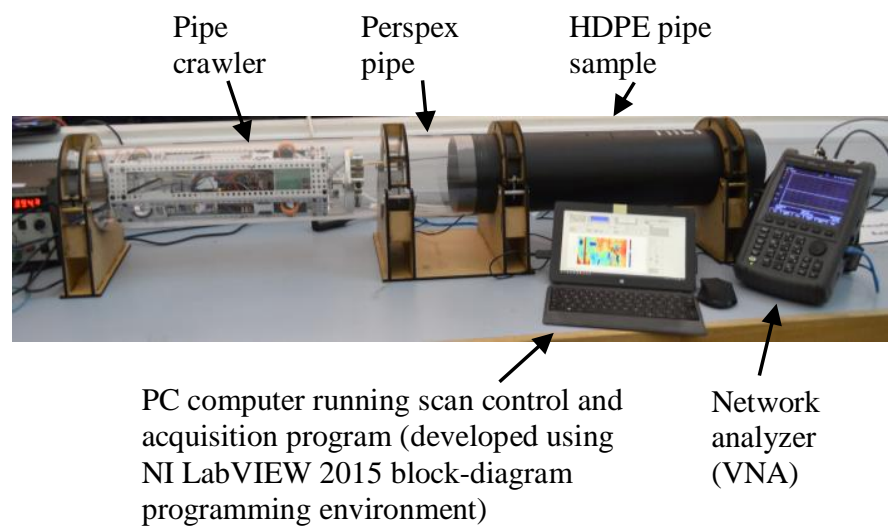

Fig. 6. Test setup for 2-dimensional scans (no foil backing).

\section{2-dimensional scanning}

2-dimensional cylindrical scans were performed on a second sample of the HDPE pipe using the prototype pipe crawler in the setup shown in Fig. 6.

Eight defects were machined onto the pipe's outer surface as shown in Fig. 7, consisting of four notches and four holes drilled partially into the pipe wall, decreasing in depth from left to right. The dimensions of the defects, given in Table III, were selected to assess and demonstrate the sensitivity of the microwave probe. The width of $1 \mathrm{~mm}$ was the minimum achievable for the manufacture of notches within the project's scope, so the ability to identify much narrower structural cracks typical of slow crack growth is a subject for future work. Notch $\mathrm{G}$ and hole $\mathrm{H}$ were cut to the Plastic Pipe Institute's [15] recommended limit of $10 \%$ of the wall thickness $-1 \mathrm{~mm}$ in depth.

Notches B, C, and G were oriented in the probe's H-plane, whereas notch $\mathrm{F}$ was cut perpendicular to the others to enable comparison between the H-plane and E-plane sensitivities on the pipe with different external environments. It should be noted that notch $\mathrm{F}$ was cut $50 \%$ wider in error.

The setup in Fig. 6 was also designed for visual demonstration of the technology and hence has a section of clear Perspex pipe attached to the left of the HDPE pipe sample, both of which supported the pipe crawler.

The pipe sample was imaged by scanning cross sections consecutively at a spacing (horizontal linear resolution) of 2 $\mathrm{mm}$, starting at just before the first defect. At each cross section, the clamp head rotated the probe through $90^{\circ}$ starting from approximately $45^{\circ}$ below the centerline of the defects, and the network analyzer was triggered $0.5^{\circ}$ into the rotation (allowing for acceleration) to take 489 samples of $S_{11}$ at a single signal frequency over $89.5^{\circ}$ of the rotation, which corresponds to 125 $\mathrm{mm}$ of the pipe's outer circumference. Scans were completed with each of the three environments around the pipe-free space (no backing), and aluminum foil backing with and without saltwater inside the defects - at the chosen optimal signal frequencies listed in Table II. The pipe crawler was adjusted to maintain the standoff distance between the probe and the pipe's inner surface within the optimal range of 1.5-3.0 $\mathrm{mm}$.

The scan images were plotted on a color scale from the
TABLE III

DIMENSIONS OF MACHINED DEFECTS ON HDPE PIPE

\begin{tabular}{lllll}
\hline \hline \multirow{2}{*}{ Defect } & Type & Width $(\mathrm{mm})$ & Length $(\mathrm{mm})$ & Depth $(\mathrm{mm})$ \\
\hline $\mathrm{A}$ & Hole* & Dia. 10.0 & & 3.3 \\
$\mathrm{~B}$ & Notch & 1.0 & 30 & 4.0 \\
$\mathrm{C}$ & Notch & 1.0 & 30 & 2.0 \\
$\mathrm{D}$ & Hole* $^{*}$ & Dia. 4.8 & & 3.3 \\
$\mathrm{E}$ & Hole* $^{*}$ & Dia. 2.8 & & 3.1 \\
$\mathrm{~F}$ & Notch & 1.5 & 29 & 2.0 \\
$\mathrm{G}$ & Notch & 1.0 & 30 & 1.0 \\
$\mathrm{H}$ & Hole* & Dia. 2.8 & & 1.5 \\
\hline
\end{tabular}

*holes were partially drilled using standard $118^{\circ}$ drill bits. The depth quoted is measured at the center of the hole.

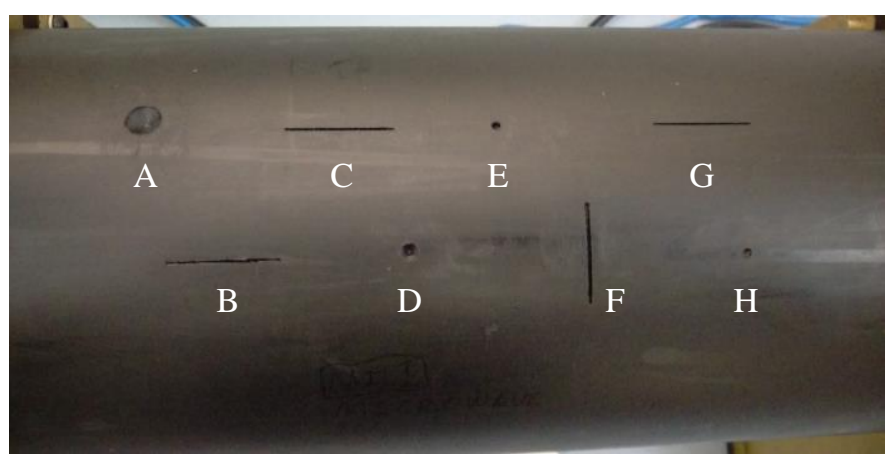

Fig. 7. Defects on outer surface of HDPE pipe sample that were scanned by the pipe crawler setup.

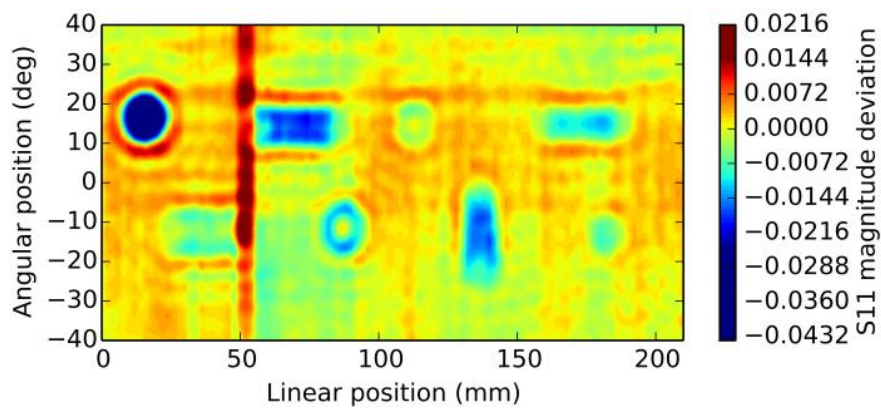

Fig. 8. Magnitude scan image at $19.5 \mathrm{GHz}$ of pipe sample without foil or impurities.

optimal component (magnitude or phase) of the $S_{11}$ measurements. Each image was processed as follows: the data in each vertical cross section were individually smoothed by a Kaiser-windowed $(\beta=6)$ moving-average filter to remove random noise, and then the entire scan was subtracted by the 2dimensional plane of best fit of itself to remove any linear trends caused by variations in standoff distance during the scan. This also subtracted the mean of the scan from the measurement values, so the image's color scale represents the difference from the mean value. The smoothing window width was 20 samples $\left(3.7^{\circ}\right)$ in the scan without foil backing, and 5 samples $\left(0.92^{\circ}\right)$ in the scans with foil backing.

The scan image in Fig. 8 is of the HDPE pipe sample without foil backing (as in Fig. 6) at $19.5 \mathrm{GHz}$. The image shows clear indications of all the defects on the pipe. The smallest defects, $\mathrm{G}$ and $\mathrm{H}$, are completely identifiable over the noise in the image. The indication on the image is generally greater in amplitude and size as defect size increases, but notch B's indication is lower in amplitude (although wider) despite the notch being greater in depth. This is due to the complexity of 


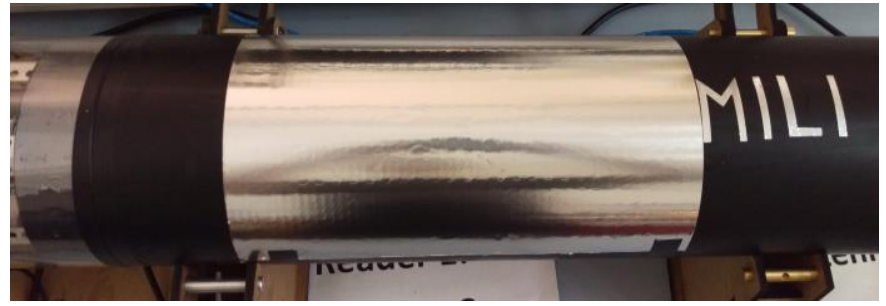

Fig. 9. Pipe sample with aluminum foil backing wrapped over the defects.

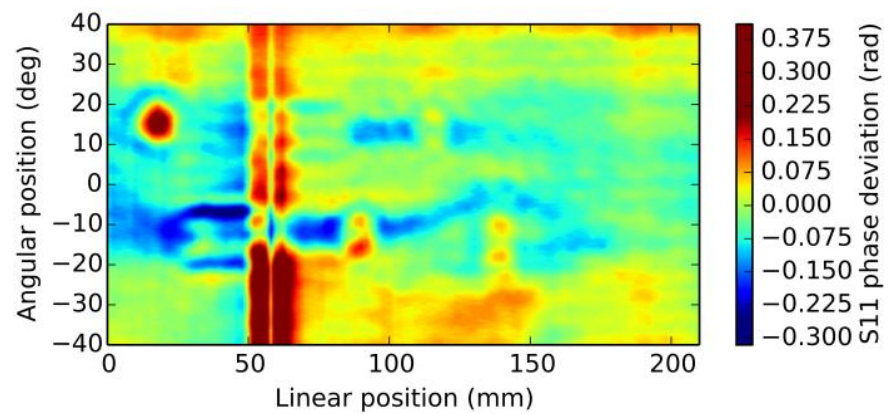

Fig. 10. Phase scan image at $24 \mathrm{GHz}$ of pipe sample with foil and without impurities.

the signal's interaction in the probe's near-field region, so different parts of the deeper notch can contribute to increases as well as decreases in the reflection coefficient's magnitude in this case. The long vertical lines at linear positions between 50 $\mathrm{mm}$ and $65 \mathrm{~mm}$ in the scan images were caused by a previously unknown inhomogeneity in the pipe material.

A second scan was performed at $24 \mathrm{GHz}$ with a reflective aluminum foil backing wrapped over the pipe surface, covering the defects as pictured in Fig. 9. The phase component of the scan, shown in Fig. 10, was slightly clearer than the magnitude component in this configuration, whereas in the free space environment (without foil backing), the magnitude component was preferred due to the lower reflection level. With the foil backing, the image in Fig. 10 has a higher level of 'noise' that completely obscures notch $\mathrm{G}$ and hole $\mathrm{H}$, and partially obscures notch $\mathrm{C}$. The reflection from the backing is much greater than the reflections from the notches, so any deformations in the backing have a large effect on $S_{11}$, obscuring the smaller indications from the air-filled notches. The larger defects can be identified by their symmetrical ripples on the image.

A further two scans were performed at $22.5 \mathrm{GHz}$ and $24 \mathrm{GHz}$ with the notches filled with saltwater of conductivity $35 \mathrm{~S} / \mathrm{m}$. The liquid was sealed in by a plastic film as illustrated in Fig. 11 , and aluminum foil was laid over the film as previously.

The magnitude scan image at $22.5 \mathrm{GHz}$ is shown in Fig. 12, and the phase scan image at $24 \mathrm{GHz}$ is shown in Fig. 13. All the defects can be clearly identified in the phase image, which can be explained by the greater amount of signal reflected from the defects when filled with conductive liquid, more comparable to that from the foil backing. The magnitude sensitivity to notch $\mathrm{C}$ is about 0.12 in saltwater according to Fig. 12, up from 0.025 in free space according to Fig. 8 . The indication of notch $\mathrm{G}$ is more pronounced in the phase image than in the magnitude image.

\section{CONCLUSIONS}

The investigations have shown that a pipe crawler with a

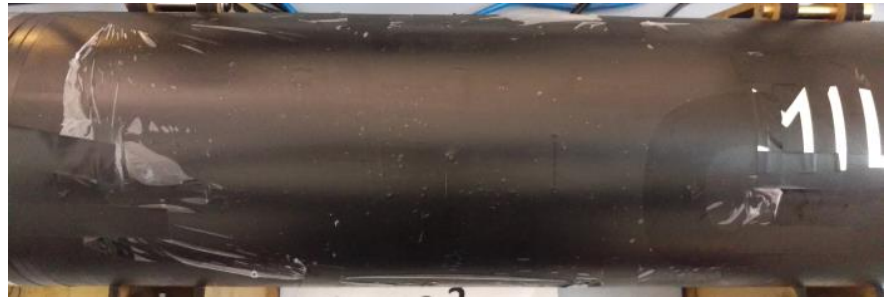

Fig. 11. Pipe sample with saltwater sealed inside defects (before aluminum foil is applied).

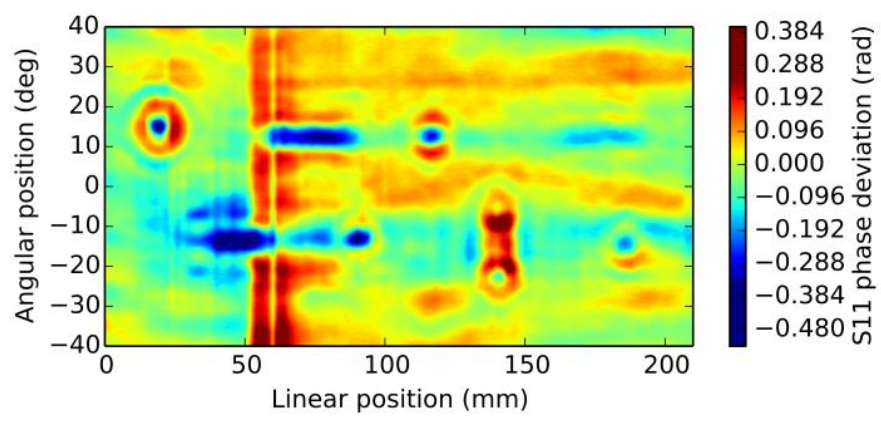

Fig. 12. Magnitude scan image at $22.5 \mathrm{GHz}$ of pipe sample with foil and saltwater in defects.

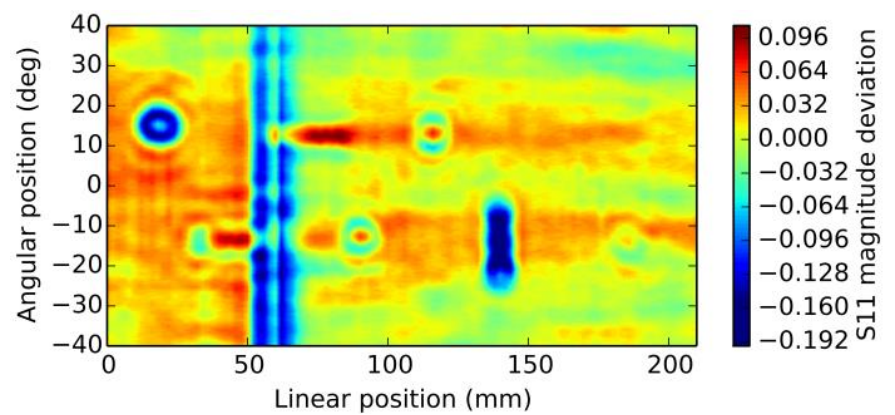

Fig. 13. Phase scan image at $24 \mathrm{GHz}$ of pipe sample with foil and saltwater in defects.

simple microwave reflectometry instrument on a rotating mount can identify a crack of width $1 \mathrm{~mm}$ and depth $1 \mathrm{~mm}$ on a 9.8 $\mathrm{mm}$-thick pipe wall in two clean, homogeneous environments of free space and saltwater. For the plastic-lined metal pipe, the indications of the smaller defects were obscured by variations in the strong background signal from the metal surface.

The probe is more sensitive to cracks oriented in its H-plane than in its E-plane. Orienting the probe's planes diagonally can afford equal sensitivity to axially- and circumferentiallyoriented cracks.

The selection of optimal combinations of frequency and standoff distance range can prevent certain variations in standoff distance from obscuring single-frequency scan images. However, each combination is specific to a single pipe wall thickness, external environment (free space, reflective material or saltwater) and choice of magnitude or phase components of the $S_{11}$ measurements. Also, some optimal combinations may only apply to a limited region across the pipe wall's thickness. This makes it necessary to tune and thoroughly test a microwave in-line inspection device for each pipe size and environment to ensure important defects can be identified.

Synthetic aperture radar techniques can clearly identify narrower cracks at greater depths in HDPE. They were shown 
in prior art to image cracks of width $0.25 \mathrm{~mm}$ on the opposite side of a $50.8 \mathrm{~mm}$-thick HDPE sheet [17], whereas the present single-frequency setup is limited to $1 \mathrm{~mm}$ crack width and 10 $\mathrm{mm}$ pipe thickness. Also, 3D SAR imaging would alleviate the problems caused by varying standoff height and inhomogeneous external environments [17], so these techniques will be considered in future work.

\section{ACKNOWLEDGMENT}

The authors would like to express their gratitude to G. Newton of Keysight Technologies UK Ltd. for kindly lending their demonstration N9918A network analyzer, and to L. Brown, J. Loftus, K. Groves, and the mechanical workshop staff at the University of Manchester for their support.

\section{REFERENCES}

[1] R. K. Krishnaswamy, "Analysis of ductile and brittle failures from creep rupture testing of high-density polyethylene (HDPE) pipes," Polymer, vol. 46, no. 25, pp. 11664-11672, Nov. 2005.

[2] M. A. M. Haniffa and F. M. Hashim, "Recent developments in in-line inspection tools (ILI) for deepwater pipeline applications," in 2011 National Postgraduate Conf., Kuala Lumpur, 2011, pp. 1-6.

[3] T. Jones, D. Polansky, and H. Berger, "Radiation inspection methods for composites," NDT Int., vol. 21, no. 4, pp. 277282, 1988.

[4] Y. Ito and T. Uomoto, "Nondestructive testing method of concrete using impact acoustics," NDT\&E Int., vol. 30, no. 4, pp. 217-222, 1997.

[5] T. Clauzon, F. Thollon, and A. Nicolas, "Flaws characterization with pulsed eddy currents NDT," IEEE Trans. Magn., vol. 35, no. 3, pp. 1873-1876, 1999.

[6] K. Murphy, and D. Lowe, "Evaluation of a novel microwave based NDT inspection method for polyethylene joints," in ASME 2011 Pressure Vessels and Piping Conf., Baltimore, Maryland, USA, 2011, pp. 321-327.

[7] X. W. Zhu, J. P. Pan, and L. J. Tan, "Microwave scan inspection of HDPE piping thermal fusion welds for lack of fusion defect," Appl. Mech. Mater., vol. 333, pp. 1523-1528, Jul. 2013.

[8] S. Kharkovsky and R. Zoughi, "Microwave and millimeter wave nondestructive testing and evaluation - overview and recent advances," IEEE Instrum. Meas. Mag., vol. 10, no. 2, pp. 26-38, Apr. 2007.

[9] O. Duran, K. Althoefer, and L. D. Seneviratne, "State of the Art in Sensor Technologies for Sewer Inspection," IEEE Sens. J., vol. 2, no. 2, pp. 73-81, Apr. 2002.

[10] C. Ékes and B. Neducza, "Robot Mounted GPR for Pipe Inspection," in $14^{\text {th }}$ Int. Conf. Ground Penetrating Radar, Shanghai, 2012, pp. 160-164.

[11] H. B. Kuntze and H. Haffner, "Experiences with the development of a robot for smart multisensoric pipe inspection," in Proc. 1998 IEEE Int. Conf. Robotics \& Automation, Leuven, May. 1998, pp. 1773-1778.

[12] P. Hutař, M. Ševčík, L. Náhlík, G. Pinter, A. Frank, and I. Mitev, "A numerical methodology for lifetime estimation of HDPE pressure pipes," Eng. Fract. Mech., vol. 78, no. 17, pp. 3049-3058, Dec. 2011.

[13] J. Q. Zhao, L. Daigle, and D. Beaulieu, "Effect of joint contamination on the quality of butt-fused HDPE pipe joints," Can. J. Civ. Eng., vol. 29, no. 5, pp. 787-798, Oct. 2002.

[14] R. Stakenborghs and J. Little, "Microwave based NDE inspection of HDPE pipe welds," in Int. Conf. Nucl. Eng., Proc., 17th, Brussels, Belgium, 2009, pp. 185-193.

[15] Handbook of Polyethylene Pipe, 2nd ed., Plastics Pipe Institute, 2008, p. 28. [Online]. Available: http://plasticpipe.org/publications/pe-handbook.html.
[16] N. Brown, "Slow crack growth-notches-pressurized polyethylene pipes", Polym. Eng. Sci., vol. 47, no. 11, pp. 1951-1955, Nov. 2007.

[17] M. T. Ghasr, K. Ying, and R. Zoughi, "3D millimeter wave imaging of vertical cracks and its application for the inspection of HDPE pipes," AIP Conf. Proc., vol. 1581, no. 1, pp. 1531-1536, 2014.

[18] C. Ziehm, S. Hantscher, J. Hinken, C. Ziep, and M. Richter, "Near field focusing for nondestructive microwave testing at $24 \mathrm{GHz}$ - Theory and experimental verification," Case Studies in Nondestructive Testing and Evaluation, vol. 6, pp. 70-78, Nov. 2016.

[19] S. Kharkovsky, P. Giri, and B. Samali, "Non-contact inspection of construction materials using 3-axis multifunctional imaging system with microwave and laser sensing techniques," IEEE Instrum. Meas. Mag., vol. 19, no. 2, pp. 6-12, Apr. 2016.

[20] M. Pastorino, Microwave Imaging. Hoboken: Wiley, 2010.

[21] Y. Deng and X. Liu, "Electromagnetic imaging methods for nondestructive evaluation applications," Sensors, vol. 11, no. 12, pp. 11774-11808, Dec. 2011.

[22] T. D. Carrigan. (2017, Jun. 12). MILI project, LabVIEW student design competition: Northern Europe. [Online]. Available: https://forums.ni.com/t5/LabVIEW-StudentDesign/MILI-project/ta-p/3643438

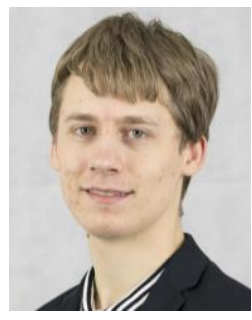

Tobias D. Carrigan received the M.Eng. degree in Electrical and Electronic Engineering in 2017 from the University of Manchester, and is now studying a Ph.D. in Engineering at the University of Cambridge. He held an electronic engineering role at Abaco Systems Ltd., Towcester, UK from August 2014 to 2015. His interests include digital signal processing, mechanical vibration, control systems and millimeter-wave electronics.

Benjamin E. Forrest, Hector N. Andem, Kaiyu Gui, and Lewis Johnson received an M.Eng. degree in Electrical and Electronic Engineering in 2017 from the University of Manchester. B. E. Forrest is now spending a semester studying Mandarin in Wuhan, China. H. N. Andem is now an electrical engineer at Bombardier Transportation UK Ltd. K. Gui is now a global FICC research analyst at Grass Capital, Shanghai. L. Johnson is currently a commissioning engineer for the tunnel ventilation system in London's Crossrail network. James E. Hibbert is studying a $\mathrm{PhD}$ on radiation damage to electronic systems at the University of Manchester.

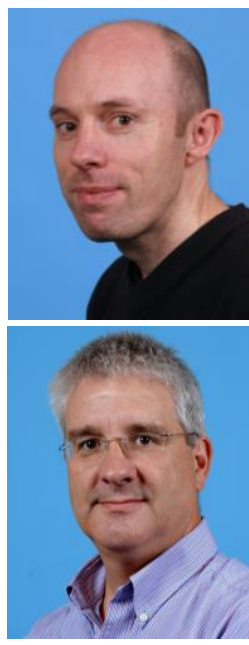

Prof. Barry Lennox is Professor of Applied Control and Nuclear Engineering Decommissioning in the School of Electrical and Electronic Engineering at The University of Manchester and is the Research Director of the Dalton Cumbrian Facility. He is an expert in applied control systems and their use in process operations and robotics and has considerable experience in transferring leading edge technology in to industry.

Prof. Robin Sloan (M'92-SM'05) is currently a Principal Analogue IC Design Engineer at Semtech EMEA Ltd., Manchester. He is also Emeritus Professor of Millimeter-wave Electronics at University of Manchester where he worked for 23 years up until October 2017. His research interests are microwave and millimeter-wave measurements, MMIC design and system architecture. He is a Royal Society Industrial Fellow (May 2014) and was a Visiting Fellow (2009 - 2017) at Keysight Technologies, Santa Rosa, USA. 